\title{
CONTRIBUIÇÃO À HISTORIOGRAFIA DA GEOGRAFIA AGRÁRIA NA UNIVERSIDADE DE SÃO PAULO
}

Prof $^{a}$ Dr $^{\mathrm{a}}$ Larissa Mies Bombardi Departamento de Geografia - USP

larissab@usp.br

\section{Resumo:}

O presente artigo tem por objetivo tecer uma historiografia da Geografia Agrária na Universidade de São Paulo, tendo em vista a importância que a linha teórica entre nós desenvolvida teve - e tem - no sentido da formação da Geografia Agrária Brasileira, em sua perspectiva crítica.

Palavras-chave: Historiografia da Geografia Agrária; Geografia Crítica; Departamento de Geografia da Universidade de São Paulo; Pensamento Geográfico na USP.

A Geografia Agrária, dentre as demais ciências humanas tem - de forma muito peculiar - contribuído enormemente para uma interpretação profícua dos movimentos sociais no campo, da recriação do campesinato e do desenvolvimento contraditório do capitalismo no campo.

Cabe-nos, portanto, resgatar e tecer o fio da construção deste pensamento.

A composição do quadro da Geografia na Universidade de São Paulo, nos primeiros anos de sua institucionalização, era feita quase exclusivamente pelo Prof. Pierre Monbeig (ressaltando que os cursos de geografia e história eram unificados), posteriormente foram formadas mais duas cátedras: a de Geografia do Brasil de Aroldo de Azevedo e a de Geografia Física de João Dias da Silveira. Estes três professores dividiram o trabalho no período da institucionalização do curso.

Monbeig, assim, formou uma equipe de auxiliares, entre eles: Ary França, Nice LeCoq Müller e Pasquale Petrone (ANDRADE, 1994, p.74).

A geografia que se cunhou, naquele momento histórico, teve como marco conceitual central o historicismo. Para exemplificar, ainda que brevemente, a geografia historicista (mesmo com forte influência do positivismo) que se formou neste período, resgato um excerto da tese de Nice Lecoq Müller defendida em 1946, sob o título: “Tipos de sitiantes em algumas regiões do Estado de São Paulo”: 
$\mathrm{O}$ rio apresenta neste trecho grande sedimentação nas margens convexas dos meandros, formando o que é chamado 'praia'; essas praias apresentam contraste com a margem côncava, de desbarrancamento, não só do ponto de vista topográfico como também da exploração do solo. Nestas o risco de enchente é pequeno, e o sitiante cultiva arroz e bananas; naquelas as inundações avançam muito para o interior e não há a possibilidade de se fazer a cultura tradicional. A inundação saturaria de água o solo e mataria as bananeiras, que exigem boa drenagem; e, como atinge seu máximo em janeiro, alcançaria o arroz em pleno período de espigamento. A solução foi a criação: formaram pastos nas partes baixas, onde aliás o gado tem nas praias fácil acesso à água, pasto esse que é utilizado até a época das enchentes, quando o gado é então levado para as partes mais altas, em pastos de reserva que sempre mantêm nas colinas. (MÜLLER, 1946, p.47)

É de se notar dois aspectos fundamentais: o primeiro que - é possível antever pelo título - diz respeito ao estudo de sitiantes como se se tratasse de comunidades isoladas, não apenas entre si, mas sem relação com o restante da sociedade. O segundo aspecto diz respeito ao fato de que a autora parte do princípio de que são as condições naturais que determinam a maneira como o espaço é apropriado (espaço aqui está sendo pensado na perspectiva de Raffestin (1993), Oliveira (1988b) e Calabi e Indovina (1973)).

Aí estão, portanto, alguns elementos dos eixos do historicismo e do positivismo presentes no pensamento geográfico (e, particularmente da geografia agrária) que foi sendo constituído na Universidade de São Paulo.

Claro está, portanto, que a geografia produzida na USP, de caráter historicista, esteve, ao mesmo tempo, marcada pelo positivismo, como apontado.

Neste sentido, de acordo com Manuel Correia de Andrade (1994), Monbeig realizou trabalhos de geografia agrária e geografia urbana, formando discípulos e atendendo aos anseios do país, do programa de modernização governamental, já que

com o avanço das relações capitalistas na economia brasileira era necessário dar ao país condições mais eficientes de exploração dos recursos naturais de que dispunha, de utilização e qualificação da força de trabalho e da implantação de estruturas que facilitassem a circulação da produção. Fatos que levaram à formação de quadros técnicos mais eficientes e mais capazes. (ANDRADE, 1994, p. 80)

Fica explícito, nas palavras de Andrade, a geografia que se consolidou na Universidade de São Paulo, atendendo às necessidades da maneira como se colocava a reprodução capitalista em curso no Brasil.

Ainda de acordo com Andrade (1994), os geógrafos influenciados por Monbeig, passaram a fazer inúmeros estudos sobre a realidade brasileira, publicando nos anais da 
AGB de 1945-1970 ${ }^{1}$ Questões sobre a migração, problemas agrários como plantations, por exemplo, foram temas de diversas teses e monografias produzidas na USP, dentro da perspectiva da geografia lablachiana, como fica claro no artigo de Manuel Correia de Andrade "O pensamento geográfico e a realidade brasileira":

Os trabalhos eram feitos com uma preocupação muito local, mediante análises de pequenas áreas e descrição de paisagens, quase sempre sem uma preocupação de generalidades, de correlação de causa e efeito, situando os problemas nacionais em um plano internacional. Isto apesar de vivermos num país onde dominava uma economia colonial exportadora, inteiramente dependente do mercado externo. Procurava-se dar à geografia um valor meramente cultural, contraponda-a em parte, à filosofia que deve ter norteado o Governo Vargas ao criar o IBGE, que deveria sr um dos esteios de sua política modernizadora de estrutura e, até certo ponto, nacionalista.

Isolando-se dos movimentos renovadores do conhecimento científico internacional, mais preocupados com os aspectos culturais da Geografia que com a sua possibilidade de utilização política e social, deram os geógrafos uma pequena contribuição ao debate dos grandes problemas nacionais como o do desenvolvimentismo, o da reforma agrária, o da industrialização, etc, que empolgaram sociólogos e economistas dos fins das décadas de 50 e 60 . Alguns geógrafos justificavam este afastamento do debate dos problemas nacionais por considerá-los não geográficos, já que admitiam uma orientação que considerava a Geografia como simples conhecimento acadêmico, sem grande interesse prático. (ANDRADE, 1977, p. 11)

Neste sentido, a reflexão que faz Carlos Walter Porto Gonçalves (1978) a respeito da abordagem lablachiana, cabe aqui também: partilha-se o real e estuda-se o "único" para escamotear a relação que lhe é subjacente.

Este quadro na geografia elaborada na Universidade de São Paulo perdurou até os anos 60. Foi, portanto, na década de 60 que passou a haver uma alteração muito significativa na concepção da geografia, no questionamento de seus pressupostos e, significativamente, a aproximação com a filosofia. Neste sentido, de acordo com OLIVEIRA, (2004) a década de 60 foi marcada pela contestação do status quo acadêmico:

O movimento estudantil, em âmbito mundial, brandiu palavras de ordem contra a ordem desigual do mundo capitalista e contra o papel ideológico da ciência no mundo do capital. Assim, a geografia não ficou, finalmente, imune à crítica. $\mathrm{O}$ encontro com a filosofia passou a permitir que o debate entre as correntes filosóficas tivesse lugar na produção acadêmica da geografia e, com ela, nascessem a crítica e a necessária contínua construção da história do pensamento geográfico.

\footnotetext{
${ }^{1}$ Monbeig, na presidência da AGB por dez anos deu a ela, segundo Andrade (1994) projeção nacional, estabelecendo assembléias anuais para as apresentações de teses e comunicações.
} 
Como conseqüência desta rebelião na base dos que produziam a ciência geográfica, estruturou-se a corrente de pensamento que tem na dialética a sua raiz filosófica. Esse movimento identificado com o ideário marxista, trouxe o diálogo com a Filosofia para a produção do conhecimento em geografia.

Neste mesmo período da história, também a influência do empirismo lógico fez com que geógrafos que seguiam essa corrente de pensamento estabelecessem diálogos com o que chamavam de Filosofia da Ciência. Incorporarando uma concepção de ciência que se pressupunha neutra, distanciaram-se do debate entre Ciência e ideologia. Suas visões axiomáticas sobre o método impediram que a reflexão abrisse lugar a uma história do pensamento geográfico marcada pela pluralidade. Edificaram um rígido caminho e autodenominaram seu método de "método científico", assumindo, assim, uma postura radical, que colocando os demais métodos como "não científicos". (OLIVEIRA, 2004, p.9-10)

Nota-se, portanto, que dois caminhos diametralmente opostos foram construídos na geografia no sentido da revisão de seus pressupostos. Um deles amplamente baseado no empirismo-lógico, no neo-positivismo e, o outro, baseado na dialética de influência marxista.

Manuel Correia de Andrade em seu artigo "O pensamento geográfico e a realidade brasileira" faz uma reflexão muito interessante sobre o surgimento do neopositivismo nas ciências humanas, não apenas na geografia, indicando seu profundo relacionamento com a expansão do capitalismo:

A expansão do sistema capitalista e a necessidade da implantação do seu modo de produção na maior extensão possível do Terceiro Mundo teria que ser feita com todas as armas e com todos os recursos disponíveis, a fim de barrar a expansão do sistema capitalista (...) Esses princípios e idéias predominaram na fase eufórica de grande crescimento econômico capitalista, em todas as ciências sociais. (...) O compromisso com o crescimento econômico não racionalizado, com o chamado "progresso", provocou a formação de escolas, nas várias ciências sociais, que procuraram abstrair as conseqüências negativas deste crescimento e projetar apenas as vantajosas, utilizando para isto o método matemático-estatístico. E a matemática e a Estatística, ciências que dão excelente contribuição quando utilizadas como meios, como instrumentos, passaram a ser utilizadas como um fim, como se os problemas econômicos e sociais não fossem também e principalmente qualitativos. O quantitativo, naturalmente, mede o fato que é em essência qualitativo. A substituição do qualitativo pelo quantitativo e o uso de indicadores numéricos com exclusividade para interpretar situações, às vezes até com a importação de uso generalizado de palavras de outras línguas, apesar de poderem ser traduzidas, foram levados ao máximo pelos economistas com a escola marginalista, pelos sociólogos com a escola funcionalista e, finalmente, pelos geógrafos com a chamada Nova Geografia ou Geografia Quântica ou Quantitativa. (ANDRADE, 1977, p. 12-13)

Com relação à Geografia Agrária, especificamente: 
Praticamente, no mesmo período em que a Geografia Agrária historicista, ainda, marcava a reflexão de grandes intelectuais ... José Alexandre Felizola Diniz preocupou-se na incorporação de novas técnicas de tratamento dos dados quantitativos, tendo como foco a realização do planejamento, mas sem salientar a existência de contradições no campo e na agricultura, muito menos em determinar a desigualdade na apropriação da riqueza socialmente produzida, sendo o que se expressa em Geografia da Agricultura, de 1986, obra de síntese de uma tendência da Geografia identificada como teórico-quantitativa. (SUZUKI, 2006, p. 11)

A tendência quantitativa que marcou a geografia no pós-guerra e, no Brasil sobretudo após os anos 60, embora tenha tido maior força em outras instituições do que na USP, na Universidade de São Paulo também se fez presente. Dentre os exemplos, vale à pena citar o trabalho "Difusão espacial da citricultura no estado de São Paulo", de Lígia C. Poltroniéri, publicado em 1976, pelo então Instituto de Geografia da USP, na série Teses e Monografias. Neste trabalho é possível enxergar com clareza o aparato quantitativista na geografia agrária construída na USP, a começar pelo título do item com que é iniciada a citação:

A mensuração como suporte das técnicas.

As técnicas empregadas para que os objetivos fossem alcançados são quantitativas e isto exige que as informações sejam mensuradas,ou expressas através de números.

Teoricamente, precisávamos para a Análise de Tendência, de uma matriz de m lugares $\mathrm{x} \mathrm{n}$ variáveis, sendo que, duas delas, referem-se aos atributos de localização no espaço e, a terceira, a um atributo que significa a importância citrícola deste espaço, nos anos de 1938, 1950, 1960 e 1970.

Para a Análise Fatorial necessitávamos de uma matriz de m lugares x $\mathrm{n}$ variáveis, estas últimas pertencentes à atividade agrícola e disponíveis nas fontes estatísticas. (...) O problema inicial que se colocou foi o da seleção dos lugares, isto é, a definição das áreas citrícolas do Estado de São Paulo, uma vez que não poderíamos colocar, na matriz de informações espaciais, todos os espaços citrícolas, em virtude do problema de limitação do Computador Eletrônico. (POLTRONIÉRI, 1976, p. 5)

Nota-se, como acentuou Manuel Correia de Andrade, que a matemática e a estatística, ao invés de serem instrumentos, passaram a ser fins em si mesmas, tanto assim, que os dados a serem utilizados foram definidos em função da limitação do "Computador Eletrônico" (com iniciais em maiúsculas).

O "quantitativo", portanto, ao invés de medir o fato qualitativo (o que em si só demanda discussão), findava-se em si mesmo.

Entretanto, a despeito do florescimento da geografia quantitativa, a outra principal raiz de pensamento que surge nesse momento no Brasil e na Universidade de São Paulo, como indicado, foi a dialética. 
Segundo Oliveira (1999, p. 69) esta foi a raiz esquecida do pensamento geográfico, que aparece em Reclus e em Kropotkin e, permaneceu completamente alijada até meados das décadas de 30 e 40 retomada por geógrafos franceses, por exemplo: Pierre George, Yves Lacoste, Raymond Guglielmo, Bernard Kayser, Jean Dresh, Jean Tricart. Acrescenta Oliveira (1999) que, muitas vezes, uma forte influência historicista marcava a obra destes autores.

A dialética, entretanto, foi trazida para o pensamento geográfico através do marxismo e, de acordo com Oliveira (1999), foi instrumento do desmascaramento do discurso "neutro" existente. O Marxismo, desta forma, sobretudo a partir dos anos 60, no Brasil, teve grande importância na compreensão da realidade e passou a haver, portanto, uma luta contra o discurso da "neutralidade científica" presente nas demais correntes do pensamento geográfico. Segundo Oliveira (1999, p.69):

... a dialética como corrente de pensamento da Geografia Agrária está na base de um conjunto de trabalhos de Orlando Valverde, Manuel Correia de Andrade, Pasquale Petrone, Léa Goldenstein, Manuel Seabra, entre outros. Essa influência tem sido marcada por princípios que sustentam esta escola de pensamento. Podese destacar entre os mesmos o condicionamento histórico e social do pensamento, portanto seu caráter ideológico de classe. Com o marxismo começa a batalha pelo desmascaramento do discurso pretensamente neutro e objetivo presente no positivismo e no empirismo lógico e mesmo no historicismo.

É de se notar que, entre estes, Pasquale Petrone, Lea Goldenstein e Manuel Seabra, compunham o corpo da Universidade de São Paulo e, imprimiram em seus trabalhos e no encaminhamento das pesquisas que orientavam uma forte influência marxista. Neste sentido, temas como a luta de classes e a divisão internacional do trabalho passaram a estar presentes nos trabalhos e pesquisas desenvolvidos.

A dialética passou a estar presente no marco teórico de parte dos trabalhos desenvolvidos.

Manuel Seabra, por exemplo, em sua obra: "Vargem Grande: organização $e$ transformações de uma parte do Cinturão Verde Paulistano" (Seabra, 1971), praticamente "abre" seu trabalho definindo uma perspectiva que superava o marco historicista da geografia:

Mas a metrópole paulistana não repercute sobre a organização do espaço econômico em Vargem Grande apenas como principal mercado consumidor dos produtos de sua atividade horti-fruti-granjeira. Se esta nos parece, dentro do tempo, o primeiro elemento de importância desta capacidade da cidade, no decorrer do seu processo de metropolização, em organizar o espaço imediato ao seu redor, muitos outros elementos, inclusive com dinamismo atual mais evidente, 
se somam hoje às atividades horti-fruti-granjeitras, disputando o espaço nesta parcela do "cinturão-verde", apagando praticamente os vestígios organizados daquilo que Pasquale Petrone denominou de "cinturão caipira" de São Paulo. (SEABRA, 1971, p.2)

Nota-se, na perspectiva de Manuel Seabra, uma interpretação tanto do Cinturão Verde, que não termina nele mesmo, assim como a própria interpretação da Metrópole Paulistana que não se explica por si só. Isto significa que o autor buscava uma compreensão que em muito extrapolava a tradição da geografia regional, ao contrário, lograva um entendimento de que o particular não se explica por ele mesmo.

Vale mencionar também que no âmbito da Geografia Agrária, há dois autores que marcam este processo de inserção do/no debate marxista e que, embora não estivessem no quadro de docentes da USP, também tiveram uma grande influência na consolidação da geografia agrária da USP, trata-se de Manuel Correia de Andrade e de Orlando Valverde.

Valverde, em sua obra "Estudos de Geografia Agrária Brasileira", afirmou que havia quem duvidasse da existência de um problema agrário brasileiro por conta da sua posição na produção agropecuária mundial ou por conta da dimensão de sua área, entretanto, argumentou que não eram estes os elementos que indicavam se havia um problema agrário ou não, mas sim, "a resposta a esta pergunta: Qual é a situação do homem rural no contexto sócio-econômico do país?" (VALVERDE, 1981, p.232).

Orlando Valverde avançou, assim, em uma direção completamente oposta àquela de seu mestre (Leo Waibel), na medida em que passou a colocar no centro de sua preocupação o contexto "sócio-econômico". Portanto, discutir a questão agrária no âmbito da geografia proposta por Valverde passava necessariamente por compreender a maneira como a terra estava sendo apropriada e o que isto significava do ponto de vista social.

Valverde, grande admirador de seu mestre Leo Waibel, deixou a "neutralidade" que era central na escola historicista e passou a uma abordagem marxista-historicista, em função de seu posicionamento político. Rompeu, de certa forma, com o próprio dualismo que vivia: o da ciência separada da compreensão e postura frente à realidade social (OLIVEIRA,1978).

Manuel Correia de Andrade caminhou em uma direção similar quando escreveu “A Terra e o Homem no Nordeste", estudando a questão agrária e procurando enxergar 
o modo de produção predominante no campo, as relações sociais e a luta pela terra (FERNANDES, 1998).

Entre os textos presentes em "Estudos de Geografia Agrária Brasileira" de Orlando Valverde, está um capítulo que havia sido escrito em 1961 chamado "Regionalização da Reforma Agrária". Nele Valverde afirmou que para a reforma agrária ser democrática, dois grupos deveriam ser ouvidos: os técnicos e os camponeses da região. Afirmou também que não se devia fazer reforma agrária em terras longínquas "assim o desejam os opositores da reforma agrária" e que o único objetivo fundamental da reforma agrária: "é o soerguimento econômico e social das populações rurais" adotando uma postura deliberadamente política, já em total consonância com sua abordagem científica.

O legado destes autores é realmente indiscutível, sobretudo quando se considera o salto teórico-metodológico dado com relação à geração anterior. Eles formaram a raiz do pensamento crítico posterior.

Foi através da influência do pensamento marxista que a dialética passou a estar presente na geografia agrária brasileira e passou, portanto, a adquirir o caráter despontado por Valverde e por Manuel Correia de Andrade.

No âmbito da geografia agrária - de sua transformação - que se consolidou nos quadros da Universidade de São Paulo, dois trabalhos merecem ser apontados: "A tese de doutorado de Maria Regina Cunha de Toledo Sader, Espaço e Luta no Bico do Papagaio, de 1986, foi um marco no adensamento de uma leitura acerca da desigual apropriação da terra no Brasil, abrindo o debate sobre os conflitos no campo brasileiro..." (SUSUKI, 2006, p. 11).

O outro trabalho foi a tese de doutorado de Ariovaldo Umbelino de Oliveira. Ariovaldo Umbelino de Oliveira que se tornou o principal representante da corrente marxista no âmbito da geografia agrária. Foi ele quem, deliberadamente, introduziu na geografia agrária - através de sua concepção dialética de ciência - o comprometimento do trabalho científico com a transformação da realidade.

De acordo com Fernandes (1998, p.106):

... um dos primeiros trabalhos de ruptura nos estudos de Geografia Agrária é a tese de doutorado de Ariovaldo Umbelino de Oliveira "Contribuição para o estudo da geografia agrária: crítica ao 'Estado Isolado' de Von Thünen". Este trabalho 'introduz os conceitos básicos do materialismo histórico e do materialismo dialético, elementos fundamentais para uma introdução crítica às ideologias dos trabalhos desenvolvidos em Geografia Agrária, particularmente no Brasil'. 
Neste âmbito é que os temas como conflitos por terra, violência e movimentos sociais no campo passaram a ser abordados por Ariovaldo Umbelino de Oliveira, de forma aberta e deliberada, marcando a geografia agrária que se consolidou a partir da Universidade de São Paulo.

Entretanto, a interpretação do campesinato, da violência e dos conflitos no campo, não tem sido a marca dos estudos em geografia agrária. Como demonstra Oliveira, no interior do marxismo a interpretação do campo, do desenvolvimento do capitalismo no campo, não só foi, como tem sido feita, por posturas teóricas, por vezes, antagônicas. Neste sentido, Oliveira indica a existência de três grandes correntes de interpretação do desenvolvimento capitalista no campo, mostrando que inúmeros autores, no próprio marxismo, "não escaparam à influência tanto do positivismo como do historicismo".

Em uma destas correntes estão os autores que defendem que no Brasil houve feudalismo, ou relações semi-feudais de produção:

Por isso eles advogam a seguinte tese: para que o campo se desenvolva seria preciso acabar com estas relações feudais ou semifeudais e ampliar o trabalho assalariado no campo. Para esses autores, a luta dos camponeses contra os latifundiários exprimiria o avanço da sociedade na extinção do feudalismo. Portanto, a luta pela reforma agrária seria um instrumento que faria avançar o capitalismo no campo. Esses autores costumam afirmar inclusive que o capitalismo está penetrando no campo. Entre os principais estudiosos que seguem essa concepção estão Maurice Dobb, Nelson Werneck Sodré, Alberto Passos Guimarães, Inácio Rangel, etc. O livro Estudos de Geografia Agrária Brasileira, de Orlando Valverde, apresenta esta interpretação... (OLIVEIRA, 1999, p.70)

Em uma segunda corrente, estão os autores que acreditam que o capitalismo irá se desenvolver até o ponto em que o campesinato irá se "diferenciar" internamente, o que significará que, por fim, haja sua própria desaparição, tendo os elementos desta classe tornado-se proletários ou capitalistas:

Outra vertente que entende que o campo brasileiro já está se desenvolvendo do ponto de vista capitalista e que os camponeses inevitavelmente irão desaparecer, pois eles seriam uma espécie de 'resíduo' social que o progresso capitalista extinguiria. Ou seja, os camponeses ao tentar produzir para o mercado acabariam indo à falência, e perdendo suas terras para os bancos ou mesmo teriam que vende-las para saldar as dívidas. Com isso, os camponeses tornar-se-iam proletários. Entre os principais pensadores dessa corrente estão Karl Kautsky, Vladimir I. Lênin, Léo Huberman, Paul Sweezy, Caio Prado Jr., Maria Conceição D'Incao e Mello, José Graziano da Silva, Ricardo Abramovay etc. A maior parte dos trabalhos em geografia agrária têm por base essa concepção. São exemplos dessa corrente ... a maior parte das teses e dissertações defendidas na Geografia da 
UNESP- Rio Claro-SP e na UFRJ no Rio de Janeiro. Mas, talvez, pelo seu caráter emblemático, o trabalho de Ruy Moreira "O desenvolvimento do capitalismo e o lugar do campo no processo" publicado na revista Terra Livre $\mathrm{n}^{\circ} 1$, seja um dos melhores exemplos dessa corrente na geografia agrária. (OLIVEIRA, 1999, p.71)

Oliveira, entretanto, se opõe às duas correntes anteriores argumentando que nelas não

há lugar histórico para os camponeses no futuro. Isso porque a sociedade capitalista é pensada por estes autores como sendo composta por duas classes sociais: a burguesia (os capitalistas) e o proletariado (os trabalhadores assalariados). É por isso que muitos autores e mesmo partidos políticos não assumem a defesa dos camponeses. (OLIVEIRA, 1999, p.71)

Para se contrapor aos autores das outras duas correntes marxistas de interpretação do campo, Oliveira afirma que:

Penso que esses autores "esqueceram" uma frase escrita por Karl Marx em O Capital: "Os proprietários de mera força de trabalho, os proprietários de capital e os proprietários de terra, cujas respectivas fontes de rendimentos são o salário, o lucro e a renda fundiária, portanto, assalariados, capitalistas e proprietários de terra, constituem as três grandes classes na sociedade moderna, que se baseia no modo de produção capitalista." Portanto, a compreensão do papel e do lugar dos camponeses na sociedade capitalista e no Brasil, em particular, é fundamental. Ou entende-se a questão no interior do processo de desenvolvimento do capitalismo no campo, ou então continuar-se-á a ver muitos autores afirmarem que os camponeses estão desaparecendo; entretanto, os camponeses continuam lutando para conquistar o acesso à terra no Brasil. Um bom exemplo para esclarecer essa questão é o aumento no número do número de posseiros no Brasil. (OLIVEIRA, 1999, p.72)

Há que se fazer um importante esclarecimento com relação à interpretação, proposta por Oliveira, sobre a existência do campesinato como classe social no modo capitalista de produção: ela é reflexo de seu posicionamento teórico. Ou seja, esta interpretação é diretamente fruto da dialética marxista. Em outras palavras, este mergulho na dialética marxista, é que o permitiu conceber a realidade como eminentemente contraditória. Neste sentido, é próprio da "condição contraditória da realidade", a existência de formas não-capitalistas no interior e no processo de produção e reprodução do capital. Assim é que o campesinato é interpretado como fruto deste desenvolvimento do capital, que ao mesmo tempo em que é contraditório, é também combinado.

É neste âmbito que foi construída na Geografia Agrária da USP a terceira corrente de interpretação do desenvolvimento do capitalismo no campo: uma corrente 
assentada no pensamento dialético, em que tem lugar a concepção da unidade dos contrários:

Dessa forma, para mim, que faço parte de uma outra concepção teórica da compreensão do desenvolvimento do capitalismo no campo, o que ocorre na agricultura brasileira é um processo diferente. O estudo da agricultura brasileira deve ser feito levando-se em conta que o processo de desenvolvimento do modo capitalista de produção é contraditório e combinado. Isso quer dizer que, ao mesmo tempo que esse desenvolvimento avança reproduzindo relações especificamente capitalistas (implantando o trabalho assalariado pela presença no campo do bóia-fria), ele (o capitalismo) produz também, igual e contraditoriamente, relações camponesas de produção (pela presença do aumento do trabalho familiar no campo). Entre os mais importantes pensadores dessa corrente estão Rosa de Luxemburg, Teodor Shanin, Samir Amin, Kostas Vergopoulos (...) (OLIVEIRA, 1999, p.73)

Neste entendimento, apontado e desenvolvido por Oliveira, não apenas a realidade é concebida como eminentemente contraditória, como há que se considerar também que é parte fundamental da concepção dialética submeter a teoria à realidade:

$\mathrm{Na}$ dialética, a teoria não pode se constituir de modo isolado da prática porque é esta que fornece conteúdo para o pensar. A prática também não pode estar desvinculada de uma teoria, razão pela qual o acervo teórico de nosso trabalho depende da prática social. (CAMPOS, 2001, p.88)

Assim, é exatamente neste âmbito que Oliveira elabora e sustenta sua teoria sobre a agricultura camponesa e, particularmente, sobre o campesinato brasileiro:

... a compreensão do papel e do lugar dos camponeses na sociedade capitalista e no Brasil, em particular, é fundamental. Ou entende-se a questão no interior do processo de desenvolvimento do capitalismo no campo, ou então continuar-se-á a ver muitos autores afirmarem que os camponeses estão desaparecendo; entretanto, os camponeses continuam lutando para conquistar o acesso à terra no Brasil. Um bom exemplo para esclarecer essa questão é o aumento no número do número de posseiros no Brasil. Um bom exemplo para esclarecer esta questão é o aumento do número de posseiros no Brasil. Em 1960, existiam 356.502 estabelecimentos agropecuários controlados por posseiros. Já em 1985, eles passaram para 1.054.542 estabelecimentos. Exatamente neste período de grande desenvolvimento do capitalismo (sobretudo industrial) ocorreu no Brasil um aumento de mais de $196 \%$ dos estabelecimentos ocupados por posseiros. (OLIVEIRA, 1999, p.72)

É, portanto, através da realidade, que Oliveira constrói e elabora seu pensamento teórico, contrapondo-se às demais correntes de interpretação do campo, e mostra o equívoco destas correntes:

Se as teses de extinção do campesinato, de fato, tivessem capacidade explicativa, esses posseiros deveriam ter se tornado proletários. Mas não foi isso o que ocorreu. Os camponeses, em vez de se proletarizarem, passaram a lutar para 
continuarem sendo camponeses. Logo, são as teses sobre a compreensão do desenvolvimento do capitalismo no campo, seguidas por esses autores que possivelmente, não têm capacidade explicativa. Na realidade, o que ocorre é que esses autores têm uma concepção teórica que deriva de uma concepção política de transformação da sociedade capitalista. Partem do pressuposto de que a chegada do socialismo só seria possível se a sociedade capitalista tivesse apenas duas classes sociais: o proletariado e a burguesia... (OLIVEIRA, 1999, p.72)

É a partir do método dialético de Marx que Ariovaldo Umbelino de Oliveira elabora e desenvolve sua teoria, concebendo a realidade como ponto de partida e de chegada. Citando o próprio Marx, mostra onde está o aspecto central de seu método:

... meu método dialético não só difere do hegeliano, mas é sua antítese direta. Para Hegel, o processo de pensamento, que ele, sob o nome de idéia, transforma num sujeito autônomo, é o demiurgo do real, real que constitui apenas a sua manifestação externa. Para mim, pelo contrário, o ideal não é nada mais que o material, transposto e traduzido na cabeça do homem. (MARX, K. 1985, apud OLIVEIRA, 1999:70)

Sua produção bibliográfica tem vários trabalhos que se tornaram emblemáticos na construção da geografia agrária brasileira na perspectiva marxista. Um destes primeiros trabalhos - que se tornou referência nesta linha de pensamento - foi sua própria tese de doutorado, que começou a ser desenvolvida com a intenção de verificar como seria a aplicação no campo paulista da teoria de Von Thünen, e acabou por tornarse exatamente seu avesso, ou seja, transformou-se na "Contribuição para o estudo da geografia agrária: crítica ao 'Estado Isolado' de Von Thünen'. Oliveira, no desenvolvimento dos estudos para a tese deu o "salto metodológico dialético", tornando-se cônscio de que a teoria não se "encaixava" à realidade e, a partir daí, fez a crítica da própria teoria estudada.

Neste sentido, e, caminhando no desvendamento do campo brasileiro a partir de uma perspectiva dialética, fundamental foi o artigo publicado no Boletim Paulista de Geografia, sob o título "Agricultura e Indústria no Brasil"2, em que Ariovaldo Umbelino de Oliveira passou a desvendar as relações não-capitalistas presentes no campo paulista, responsáveis pela produção do capital no campo.

A partir daí, diversas foram as obras3 de desvendamento do campo nesta mesma perspectiva, em que se completava o ciclo de sua postura dialética, no sentido de que sua trajetória foi marcada não só pela interpretação da realidade como também por seu compromisso com a transformação social da realidade.

\footnotetext{
${ }^{2}$ OLIVEIRA, 1981.

${ }^{3}$ Entre estas, ver: OLIVEIRA (1984; 1985; 1986a; 1986b; 1990; 1991a; 1991b; 1995a; 1995b; 1996; $2001 b ; 2002 ; 2003 b ; 2004)$.
} 
Trilhando este caminho, Oliveira tornou-se uma referência para os estudos dos movimentos sociais no campo - não só na geografia, como nas outras ciências humanas - produzindo uma interpretação teórica para a reprodução do campesinato e dos movimentos camponeses.

A interpretação teórica dos movimentos sociais, no âmbito da geografia, tornouse, portanto, uma das grandes marcas do pensamento de Ariovaldo Umbelino de Oliveira.

Esta marca está, sem dúvida, relacionada também à sua historicidade. Os movimentos sociais no campo que grassaram a realidade brasileira a partir da década de 80 puseram na ordem do dia a questão dos conflitos e, sem dúvida, também do próprio campesinato.

De alguma maneira, os movimentos sociais no campo, têm pautado uma parcela significativa dos trabalhos em geografia agrária desenvolvidos no Brasil, mas sobretudo na Universidade de São Paulo, a partir da perspectiva já apontada, cunhada por Oliveira.

Há que considerarmos - novamente retomando a concepção de "Visão Social de Mundo", proposta por Löwy - que o pensamento tem lugar no mundo concreto, não é, evidentemente, desconectado do real, mas também fruto dele.

Como afirma Damiani (2008):

A história do pensamento está imersa na história humana. Embora existam, ao longo de séculos, explicações metafísicas, quanto ao movimento do pensamento, isto é, interpretações que separam o real prático e humano e o conhecimento humano, a atividade do pensamento se define como uma possibilidade da história do homem. Não coincidem, exatamente, o real e o pensamento, isto é, o que existe não é, imediatamente e sem mediações, definido como pensamento. A idéia da esponja, que porosa, absorve a água, pode ser interessante como metáfora desse processo. Se considerarmos a água como o real, propriamente, o conhecimento não se assemelharia a uma esponja, que imediatamente sorveria a água. Entre o real concreto e o real pensado existe um movimento, por si só, extremamente complexo. Contudo, no limite último, a afirmação de que não há conhecimento estritamente abstrato, explicado como uma substância transcendental, transcendente ao real concreto, é uma premissa da compreensão do conhecimento, segundo uma concepção materialista da história.

$\mathrm{O}$ desenvolvimento do pensamento, ao longo do tempo histórico, implicou o conhecimento de conceitos gerais, ou melhor, o desenvolvimento das abstrações no plano do pensamento, que sintetizaram e elevaram um corpo de observações concretas, mais pontuais e individuais, a rigor, particulares. Da potência das generalizações, como ato de conhecimento, derivou uma explicação metafísica do pensamento, transcendente ao real: o homem tangido pelo Espírito Puro, superando o homem comum, seria o sujeito do conhecimento. E a verdade do real, ou o real verdadeiro, revelados pelo conhecimento, seriam anteriores ao próprio real, que se resumiria, no estrito limite, a manifestações inacabadas dessa verdade 
total e absoluta. Define-se, então, a essência do idealismo: o absoluto do pensamento ou o pensamento como absoluto.

Uma concepção materialista do conhecimento, produto do próprio desenvolvimento da história humana, evocaria a relação necessária entre o real e o pensamento, superando a metafísica idealista. A própria história humana explica a existência do idealismo; assim como, a possibilidade de sua superação. (Damiani, 2008:42).

Uma outra marca - desta construção iniciada por Oliveira - é aquela ressaltada por Júlio Suzuki, e diz respeito à construção de uma teoria relacionada aos mecanismos de renda da terra no capitalismo:

Vale ... mencionar a diferenciação de Ariovaldo Umbelino de Oliveira (1999) entre territorialização do capital e monopolização do território, que muito ajudou a entender o significado do trabalho subordinado à lógica de reprodução ampliada do capital e de acumulação primitiva ora como trabalho camponês integrado e subordinado, quando ocorre a monopolização do território, ora como trabalho assalariado, quando ocorre a territorialização do capital, servindo de fundamento para muitas das reflexões feitas sobre o tema da modernização da agricultura ... (SUZUKI, 2006, p. 13)

Neste marco conceitual marxista, Oliveira formou uma gama muito grande de geógrafos agrários sob sua orientação, ainda de acordo com Suzuki:

Nas três últimas décadas, sob orientação de Ariovaldo Umbelino de Oliveira, consolidou-se uma Geografia Agrária do Campesinato, com perspectivas e dimensões bastante distintas, avançando no entendimento de suas primeiras reflexões sobre renda da terra (OLIVEIRA, 1978 e 1986) e o significado da produção camponesa na formação da riqueza oriunda do campo e da agricultura (OLIVEIRA, 1990 E 1991a).

Estes trabalhos têm sido realizados sobre, dentre outras, algumas temáticas centrais, a saber: movimentos sociais, reforma agrária, agroindústria e populações tradicionais.

Entre muitos outros, vale à pena destacar os trabalhos de Virgínia Etges: "Sujeição e Resistência - Os camponeses gaúchos e a indústria do fumo" (Mestrado em Geografia Humana) e "Geografia Agrária: a contribuição de Leo Waibel” (Doutorado em Geografia Humana); Larissa Mies Bombardi “Campesinato, luta de classe e reforma agrária (A Lei de Revisão Agrária em São Paulo)" (Doutorado em Geografia Humana) e "O Bairro Reforma Agrária e o processo de territorialização camponesa" (Mestrado em Geografia Humana); Carlos Alberto Feliciano "O Movimento Camponês Rebelde e a Geografia da Reforma Agrária” (Mestrado em Geografia Humana); Bernardo Mançano Fernandes "MST: Formação e Territorialização" e "Contribuição ao Estudo do Campesinato Brasileiro: formação e territorialização do Movimento dos Trabalhadores 
Rurais Sem Terra MST - 1979 - 1999” (Doutorado em Geografia Humana): Marcelo Justo " Exculhidos": ex-moradores de rua como camponeses num assentamento do MST." (Doutorado em Geografia Humana); Marta Inês Medeiros Marques "O modo de vida camponês sertanejo e sua territorialidade no tempo das grandes fazendas e nos dias de hoje em Ribeira - PB." (Mestrado em Geografia Humana) e "De sem-terra a "posseiro", a luta pela terra e construção do território camponês no espaço da reforma agrária: o caso dos assentados nas fazendas Retiro e Velha - GO" (Doutorado em Geografia Humana); Marco Antonio Mitidiero Jr "O movimento de libertação dos sem terra (MLST) e as contradições da luta pela terra no Brasil"' (Mestrado em Geografia Humana), Márcia Mizuzaki “Monopolização do Território e Reestruturação Produtiva na Avicultura em Mato Grosso do Sul" (Doutorado em Geografia Humana), Mirian Claudia Lourenção Simonetti “A Longa caminhada: A (re)construção do território camponês em Promissão" (Doutorado em Geografia Humana); Antonio Thomaz Jr “A Territorialização do Monopólio: as agroindústrias canavieiras em Jaboticabal" (Mestrado em Geografia Humana).

Assim, Suzuki, remete-se, como foi visto - à esta construção teórica - como a elaboração/construção de uma Geografia Agrária do Campesinato, tornando-se a Geografia Agrária da USP um marco teórico para Geografia Agrária que vem se desenvolvendo em todo o país.

Há ainda que ressaltar os trabalhos em Geografia Agrária na Universidade de São Paulo elaborados e orientados por três professoras que tiveram uma importância muito grande no debate e, igualmente, em parcela significativa desta construção teórica, são elas: a $\operatorname{Prof}^{\mathrm{a}} \operatorname{Dr}^{\mathrm{a}}$ Iraci Palheta, a $\operatorname{Prof}^{\mathrm{a}} \operatorname{Dr}^{\mathrm{a}}$ Regina Sader (1987) e a $\operatorname{Prof}^{\mathrm{a}} \operatorname{Dr}^{\mathrm{a}}$ Rosa Esther Rossini (1988). Iraci Palheta orientou inúmeros trabalhos enfocando o campesinato e sua reprodução na sociedade capitalista, na mesma perspectiva teórica do Professor Ariovaldo U. de Oliveira; a Prof ${ }^{a}$ Rosa Esther Rossini se dedicou ao estudo do êxodo rural e das relações de trabalho e gênero no campo (sobretudo na lavoura canavieira) e a Prof ${ }^{a}$ Regina Sader que, como foi apontado, inaugurou os estudos sobre conflitos no campo na Geografia da USP, igualmente na perspectiva teórica de que o capitalismo avança reproduzindo relações tipicamente capitalistas, mas ao mesmo tempo, e contraditoriamente, produz relações camponesas de produção. Regina Sader passou também a incorporar em suas reflexões e, na orientação de trabalhos, a perspectiva da fenomenologia, buscando adentrar no universo do imaginário. Esta 
perspectiva fica clara na introdução de seu artigo: "Indígenas e camponeses: uma relação de conflitos":

Este artigo visa tecer algumas considerações sobre a imagem que ao longo do tempo foi sendo construída dos indígenas por certos setores da população que hoje ocupa porções do oeste do município de Imperatriz, às margens do Tocantins.

Nessa área encontrei historiadores locais, que procuraram, ao escrever seus livros, perpetuar fatos que viveram ou escutaram dos habitantes mais antigos. Consideroos uma excelente fonte de informações na medida em que perpetuaram uma história oral. Não se trata de uma história acadêmica, porquanto tais autores não têm nenhuma formação nesse nível. Na busca dos fatos consigo o registro do que os mesmos significaram e ainda hoje significam no imaginário dessas populações camponesas ou não, no momento sob minha lente de pesquisadora. Não há possibilidade de reconstituições sob uma ótica positivista. Se a realidade é construída socialmente e se devo analisar o processo em que este fato ocorre (Berger e Luckmann, 1978), então, são esses a quem chamo de historiadores locais que, juntamente com os camponeses entrevistados, possibilitam que eu alcance meus objetivos. (SADER, 1996, p. 151)

Nota-se, portanto, na reflexão de Regina Sader, uma perspectiva de pesquisa que visa abarcar uma situação conflituosa no campo a partir do imaginário e do resgate da memória, forjando, portanto, um outro caminho para a compreensão, por exemplo, das situações de conflito.

O conflito, a contradição e a luta de classes estiveram no eixo central da preocupação da Geografia Agrária desenvolvida na USP, contrariando uma perspectiva linear e desenvolvimentista e, colaborando, portanto, com uma interpretação do campesinato, dos movimentos sociais e dos conflitos no campo. Como pontuou Antonio Candido - em debate por ocasião da invasão da PM ao Campus da USP (junho de 2009) e, especificamente, à violência perpetrada nas dependências do Departamento de Geografia da USP: a Faculdade de Filosofia foi o lócus do pensamento crítico brasileiro (e, paulista, sobretudo), em que tiveram lugar os estudos que tomavam em consideração as chamadas classes subalternas.

Neste sentido, a Geografia Agrária instaurada em nosso Departamento, contribuiu e contribui com a construção do pensamento crítico brasileiro, selando o papel que classicamente a Faculdade de Filosofia desenvolveu. 


\section{Bibliografia}

ANDRADE, M. C. de. A Terra e o Homem no Nordeste. Ed. Brasiliense, São Paulo, 1967.

. "O Pensamento Geográfico e a Realidade Brasileira". In: Boletim Paulista de Geografia, n 54, Associação dos Geógrafos Brasileiros, São Paulo, 1977, p. 5-28.

PREFÁCIO. In_ (Org.); Fernandes, F. (Coord.) Élisée Reclus. São Paulo: Ed. Ática, 1985. (Geografia).

.Geografia. Ciência da sociedade. São Paulo: Editora Atlas, 1992.

.Caminhos e descaminhos da Geografia. Campinas: Papirus, 1993.

. "Pierre Monbeig e o pensamento Geográfico no Brasil". In: Boletim Paulista de Geografia, n ${ }^{\mathbf{0}}$ 72, Associação dos Geógrafos Brasileiros, São Paulo, 1994, p. 63-82.

BOMBARDI, L. M. Campesinato, luta de classe e reforma agrária (A Lei de Revisão Agrária em São Paulo). São Paulo, 2005. Tese (Doutorado em Geografia Humana). Departamento de Geografia, Faculdade de Filosofia, Letras e Ciências, Universidade de São Paulo.

. O Bairro Reforma Agrária e o processo de territorialização camponesa. São Paulo, Anna Blume, 2004a.

"Geografia agrária e responsabilidade social da ciência". In: Terra Livre. $\mathrm{n}^{\circ} 21$, São Paulo, 2004c. p. 41-53.

BRAY, S. C. "O Pensamento e o método na obra de Pierre Monbeig - análise dos trabalhos produzidos no Brasil nas décadas de 30 e 40". In: Revista de Geografia da UNESP, Volume 2, São Paulo, 1983, p. 83-90.

"Os postulados da análise funcionalista na Geografia e seus aspectos ideológicos". In: Boletim Paulista de Geografia, $\mathrm{n}^{\mathrm{o}}$ 54, Associação dos Geógrafos Brasileiros, São Paulo, 1977, p. 29-40.

CALABI, D., INDOVINA, F. "Sobre o uso capitalista do território". In: Archivio di Studi Urbani e Regionali, Veneza, anno IV, n.2, 1973. Tradução: Liliana L. Fernandes e Moacyr Marques. 17p. (Mimeogr.).

CAPEL, H. Filosofia y ciencia en la Geografía Contemporánea. Barcelona: Barcanova, 1983.

CAPEL, H.; URTEAGA, L. Las nuevas geografias. Barcelona: Salvat Editores; 1984.

DAMIANI, A. L. Espaço e Geografia: Observações de método. Elementos da obra de Henri Lefebvre e a Geografia. Ensaio sobre Geografia Urbana a partir da Metrópole de São Paulo. São Paulo, 2008. Tese de Livre Docência. Departamento de Geografia, Faculdade de Filosofia, Letras e Ciências Humanas, Universidade de São Paulo.

ESCOLAR, M. Crítica do Discurso Geográfico. São Paulo: Hucitec, 1993. 
ESTÉBANEZ, J. Tendência y Problemática Actual de la Geografía. Madrid: Ance, 1982.

ETGES, V. E. Sujeição e Resistência - Os camponeses gaúchos e a indústria do fumo. São Paulo, 1989. Dissertação (Mestrado em Geografia Humana). Departamento de Geografia, Faculdade de Filosofia, Letras e Ciências Humanas, Universidade de São Paulo.

. Geografia Agrária: a contribuição de Leo Waibel. São Paulo, 1997. Tese (Doutorado em Geografia Humana). Departamento de Geografia, Faculdade de Filosofia, Letras e Ciências Humanas, Universidade de São Paulo.

FELICIANO, C. A. A geografia dos assentamentos rurais no Brasil: o MST e MAST no Pontal do Paranapanema. São Paulo, 1999, (Trabalho de Graduação Individual apresentado ao Departamento de Geografia, Faculdade de Filosofia, Letras e Ciências Humanas da Universidade de São Paulo, para obtenção do título de Bacharel em Geografia).

O Movimento Camponês Rebelde e a Geografia da Reforma Agrária. São Paulo, 2003. Dissertação (Mestrado em Geografia Humana). Departamento de Geografia, Faculdade de Filosofia, Letras e Ciências Humanas, Universidade de São Paulo.

FERNANDES, B. M. MST: Formação e Territorialização. São Paulo: Editora HUCITEC, 1996.

"Questões teórico-metodológicas da pesquisa geográfica em assentamentos de reforma agrária”. In: Boletim Paulista de Geografia, $\mathrm{n}^{\mathrm{0}} 75$, Associação dos Geógrafos Brasileiros, São Paulo, 1998, p. 83-129.

Contribuição ao Estudo do Campesinato Brasileiro: formação e territorialização do Movimento dos Trabalhadores Rurais Sem Terra MST 1979 - 1999. São Paulo, 1999. Tese (Doutorado em Geografia Humana). Departamento de Geografia, Faculdade de Filosofia, Letras e Ciências Humanas da Universidade de São Paulo.

FERNANDES, L. L. O Bairro Rural dos Pires. São Paulo: IG - Teses e Monografias, 1971.

GEORGE, P. et. al. Geografia Ativa. São Paulo/Rio de Janeiro: Difel, 1980.

GONÇALVES, C. V. P. “A geografia está em crise. Viva a geografia!”. In: Boletim Paulista de Geografia, n55, Associação dos Geógrafos Brasileiros, São Paulo, 1978, p. 5-29.

- Da Geografia às Geo-grafias. Texto apresentado na II Conferencia Latinoamericana y Caribeña de Ciencias Sociales. Grupo de Trabajo de Economía Internacioanal. Universidad de Guadalajara, México, 21-22 de Noviembre de 2001. mimeo. 41p.

JUSTO, M. G. "Exculhidos": ex-moradores de rua como camponeses num assentamento do MST. São Paulo, 2005. Tese (Doutorado em Geografia Humana) - Departamento de Geografia, Faculdade de Filosofia, Letras e Ciências Humanas, Universidade de São Paulo. 
KROPOTKIN, P. "Teoria e Método". In: Seleção de Textos, AGB, n¹3, São Paulo, 1986.

. Palavras de um revoltado. São Paulo: Ícone Editora/Editora Imaginário,

LA BLACHE, P. V de. "Os gêneros de vida na geografia humana. Primeiro Artigo". Annales de Geographie, n.111, ano XX, maio, 1911. Tradução: Regina Sader e Simone Ferreira.

- "Os gêneros de vida na geografia humana. Segundo Artigo". Annales de Geographie, n.112, ano XX, julho, 1911. Tradução: Regina Sader e Simone Ferreira.

LACOSTE, Y. "Geografia”. In: CHÂTELET, François (Org) A Filosofia das Ciências Sociais. Rio de Janeiro: Zahar Editores, 1981. p. 221-274.

. "Le passé des territories". Herodote (Paris), n. 74, $3^{\circ}$ trimestre, p.3-5. 1984.

."Entretien avec Georges Duby". Herodote (Paris), n.75, 4 trimestre, p.7-13. 1984.

. "A pesquisa e o trabalho de campo: um problema político para os pesquisadores, estudantes e cidadãos.” In: Seleção de Textos. n.11. Associação dos Geógrafos Brasileiros, São Paulo, agosto de 1985.

.A Geografia - isso serve, em primeiro lugar, para fazer a guerra. Campinas: Papirus, 1988.

LÖWY, M. As Aventuras de Karl Marx contra o Barão de Münchausen: marxismo e positivismo na sociologia do conhecimento. São Paulo: Ed. Busca Vida,1987.

LUXEMGBURG, R. A Acumulação do Capital. Rio de Janeiro: Zahar Editores, 1970.

MACHADO, L. O. Origens do pensamento geográfico no Brasil: Meio tropical, espaços vazios e a idéia de ordem (1870-1930). Marrakech, 1994. 33p. (Trabalho originalmente apresentado no Symposium International Théo du milieu et aménagement).

MARQUES, M. I. M. O modo de vida camponês sertanejo e sua territorialidade no tempo das grandes fazendas e nos dias de hoje em Ribeira - PB. São Paulo, 1994. Dissertação (Mestrado em Geografia Humana) - Departamento de Geografia, Faculdade de Filosofia, Letras e Ciências Humanas, Universidade de São Paulo.

.De sem-terra a "posseiro", a luta pela terra e construção do território camponês no espaço da reforma agrária: o caso dos assentados nas fazendas Retiro e Velha - GO. São Paulo, 2000. Tese (Doutorado em Geografia Humana)

- Departamento de Geografia, Faculdade de Filosofia, Letras e Ciências Humanas, Universidade de São Paulo.

MARTINS, J. S. O Cativeiro da Terra. 6a edição. São Paulo: HUCITEC, 1996 a. 
O tempo da fronteira: retorno à controvérsia sobre o tempo histórico da frente de expansão e da frente pioneira. Tempo Social, Revista de Sociologia da USP, volume 8, nº 1, 25-70, São Paulo, maio, 1996.

Fronteira. A degradação do Outro nos confins do humano. São Paulo: HUCITEC, 1997.

MARX, K. O Capital. Livro III, cap. XXIV - A Assim Chamada Acumulação Primitiva. São Paulo, Abril Cultural, 1982.

O Capital. Livro III, Vol. V. Seção VI - Metamorfose do sobrelucro em

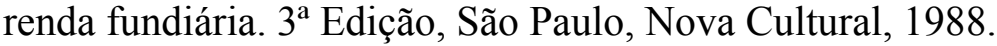

MATTOS, D. L. de, Vinhedos e viticultores de São Roque e Jundiaí. São Paulo, 1951. (Tese apresentada ao concurso para o provimento da cátedra de Geografia Humana, da Faculdade de Filosofia, Letras e Ciências Humanas da Universidade de São Paulo).

MITIDIERO JR, M. A. O movimento de libertação dos sem terra (MLST) e as contradições da luta pela terra no Brasil. São Paulo, 2002. Dissertação (Mestrado em Geografia Humana) - Departamento de Geografia, Faculdade de Filosofia, Letras e Ciências Humanas, Universidade de São Paulo.

MIZUSAKI, M. Y. Monopolização do Território e Reestruturação Produtiva na Avicultura em Mato Grosso do Sul. São Paulo, 2003. Tese (Doutorado em Geografia Humana) - Departamento de Geografia, Faculdade de Filosofia, Letras e Ciências Humanas, Universidade de São Paulo.

MONBEIG, P. Pioneiros e Fazendeiros de São Paulo. São Paulo: HUCITEC/Polis, 1984.

MONTEIRO, C. A. de F. A Geografia no Brasil (1934-1977). SãoPaulo: Instituto de Geografia da Universidade de São Paulo, 1980.

MORAES, A. C. R. de. “Território". In: Orientação, n.5, p.91. IGEOG/USP, São Paulo, 1984.

.Território e história no Brasil. São Paulo: HUCITEC/Annablume, 2002.

MOREIRA, R. "Assim se passaram dez anos - a renovação da Geografia no Brasil no período de 1978 a 1988". In: Geographia - Revista da Pós-Graduação em Geografia do Departamento de Geografia da Universidade Federal Fluminense. Ano II, no 3, Niterói, 2000a, p. 27-49.

"Nossos Clássicos: Alfred Hettner (1859-1941)". In: Geographia Revista da Pós-Graduação em Geografia do Departamento de Geografia da Universidade Federal Fluminense. Ano II, no 3, Niterói, 2000b, p. 141-142.

MOTOYAMA, S. et. al. USP 70 Anos. Imagens de uma história vivida. São Paulo: Edusp. 2006.

MÜLLER, N. L. Tipos de sitiantes em algumas regiões do Estado de São Paulo. São Paulo, 1946. Tese (Doutorado em Geografia Humana) apresentada à Cadeira de Geografia Humana da Faculdade de Filosofia, Letras e Ciências Humanas da Universidade de São Paulo. 
OLIVEIRA, A. U. Contribuição para o estudo da geografia agrária: crítica ao 'Estado Isolado' de Von Thünen. Tese de Doutorado, Departamento de Geografia, FFLCH/USP. São Paulo, 1978.

."Agricultura e Indústria no Brasil". In: Boletim Paulista de Geografia, n.58, AGB, São Paulo, 1981.

. "O Campo Brasileiro no Final dos Anos 80". In: Boletim Paulista de Geografia, nº6, Associação dos Geógrafos Brasileiros, São Paulo, 1988a.

- "Espaço e Tempo, compreensão materialista dialética". In: Milton Santos (Org.), Novos Rumos da Geografia Brasileira. São Paulo: HUCITEC, 1988b. p.66-110.

. Modo Capitalista de Produção e Agricultura. São Paulo: Editora Ática, 1990. (Princípios).

- A Agricultura Camponesa no Brasil. São Paulo: Editora Contexto, 1991.

"A mundialização do capitalismo e a geopolítica mundial no fim do século XX”. In: ROSS, J.L.S. (Org.), Geografia do Brasil. São Paulo: Edusp, 1995a.

. “Agricultura Brasileira: Transformações Recentes". In: ROSS, J.L.S. (Org.), Geografia do Brasil. São Paulo: Edusp.1995b.

"A Geografia Agrária e as Transformações Territoriais Recentes no Campo Brasileiro". In: CARLOS, A. F. A. (Org.), Novos Caminhos da Geografia. São Paulo, Contexto, 1999.

- A Geografia das Lutas no Campo: conflitos e violência, movimentos sociais e resistência, os "sem-terra" e o neoliberalismo. São Paulo, Contexto, 2001.

- "Barbárie e modernidade: as transformações no campo e o agronegócio no Brasil”". In: Terra Livre, São Paulo, Ano 19, v.2, no 21. p.113156. Jul-Dez. 2003.

. "Prefácio". In: SPOSITO, E. S. Geografia e Filosofia. Contribuição para o ensino do pensamento geográfico. São Paulo: Editora da UNESP, 2004.

PETRONE, P. "Geografia Humana”. In: MOTOYAMA, S.; FERRI, M.G. (Orgs). História das Ciências no Brasil. São Paulo, E.P.U. Editora da Universidade de São Paulo, 1979.

. "O Ensino de Geografia nos últimos 50 anos". In: Orientação, n. 10, IGEOG/USP, São Paulo, 1993. p.13-17.

. "Pasquale Petrone e a Geografia na USP". (entrevista). In: Revista Estudos Avançados, São Paulo, vol. 8, n²2, 1994. p. 139-150.

- Faculdade de Filosofia: instrumento de mudança e modernização. Discurso proferido quando da entrega do título de Professor Emérito. São Paulo: Humanitas, 1998. 
POLTRONIÉRI, L. C. Difusão espacial da citricultura no estado de São Paulo. São Paulo: Instituto de Geografia da USP, 1976.

QUAINI, M. A construção da Geografia Humana. Rio de Janeiro: Paz e Terra, 1983.

RAFFESTIN, C. Por uma geografia do poder. São Paulo: Editora Ática, 1993.

RECLUS, É. “A natureza da geografia”. In: ANDRADE, M. C. de (Org.); Fernandes, F. (Coord.) Élisée Reclus. São Paulo: Ed. Ática, 1985a. (Geografia)

. "A Origem da família, do Estado e da propriedade". In: ANDRADE, M.

C. de (Org.); Fernandes, F. (Coord.) Élisée Reclus. São Paulo: Ed. Ática, 1985b. (Geografia).

ROSSINI, R. E. Geografia e gênero: a mulher na lavoura canavieira paulista. São Paulo. 1988. Tese de Livre Docência em Geografia da População. Departamento de Geografia, Faculdade de Filosofia, Letras e Ciências Humanas, Universidade de São Paulo.

. "As geografias da modernidade - geografia e gênero - mulher, trabalho e família. O exemplo da área de Ribeirão Preto - SP”. In: Revista do Departamento de Geografia, Universidade de São Paulo, nº12, São Paulo, 1998, p. 7-26.

SADER, M.R. Espaço e luta no Bico do Papagaio. São Paulo. 1987. Tese (Doutorado em Geografia Humana) - Departamento de Geografia, Faculdade de Filosofia, Letras e Ciências Humanas, Universidade de São Paulo.

"A luta dos trabalhadores rurais sem terra". AGB Informa (São Paulo). $\mathrm{n}$. $59,4^{\circ}$ trimestre/1995.

. "Indígenas e Camponeses: uma relação de conflitos". In: Imaginário Revista do Núcleo Interdisciplinar do Imaginário e Memória. NIME/USP, nº 3, São Paulo, 1996, p. 151-161.

SADER, M.R., PACHECO, R. Modernidade, Tradição e Ruptura - Algumas Reflexões Sobre Aspectos da Paisagem Rural Brasileira. São Paulo. s.d., 9p. (Mimeogr.).

SANTOS, M. Por uma Geografia Nova. 3ª edição. São Paulo: Editora Hucitec. 1990. . Metamorfoses do Espaço Habitado. São Paulo: Editora Hucitec, 1996. Espaço e Método. São Paulo: Nobel, 1997.

SCARIN, P. C. Coetâneos da Crítica. Uma contribuição ao estudo do movimento de renovação da Geografia Brasileira. São Paulo, 2000. Dissertação (Mestrado em Geografia Humana) - Departamento de Geografia, Faculdade de Filosofia, Letras e Ciências Humanas da Universidade de São Paulo.

SEABRA, M. Vargem Grande: organização e transformações de uma parte do Cinturão Verde Paulistano. São Paulo. 1971. Tese (Instituto de Geografia) Universidade de São Paulo.

SHANIN, T. "El campesinado como factor politico". In: Campesinos y sociedades campesinas. México: Fondo de Cultura Economica, 1979. 
- La clase incomoda: sociologia politica del campesinado en una sociedad en desarrollo (Rusia 1910-1925). Madrid: Alianza Editorial, 1983.

SILVA, S. R. da. Camburi, território de brancos, negros e índios no limite do consenso caiçara : transformações de uma população tradicional camponesa. São Paulo, 2004. Dissertação (Mestrado em Geografia Humana) - Departamento de Geografia, Faculdade de Filosofia, Letras e Ciências Humanas da Universidade de São Paulo.

SIMONETTI, M. C. L. A Longa caminhada: A (re)construção do território camponês em Promissão. São Paulo, 1999. Tese (Doutorado em Geografia Humana) Departamento de Geografia, Faculdade de Filosofia, Letras e Ciências Humanas da Universidade de São Paulo.

SPOSITO, E. S. - Geografia e Filosofia. Contribuição para o ensino do pensamento geográfico. São Paulo: Editora da UNESP, 2004.

SUERTEGARAY, D. M. A. "Pesquisa de Campo em Geografia". In: Geographia Revista da Pós-Graduação em Geografia do Departamento de Geografia da Universidade Federal Fluminense. Ano IV, no 7, Niterói, 2002b, 5p.

SUZUKI, J. C. “Geografia Agrária: gênese e diversidade”. In: XVIII Encontro Nacional de Geografia Agrária, Rio de Janeiro, 2006, 24p.

THOMAZ, JR. - A Territorialização do Monopólio: as agroindústrias canavieiras em Jaboticabal. São Paulo, 1988. Dissertação (Mestrado em Geografia Humana). Departamento de Geografia, Faculdade de Filosofia, Letras e Ciências Humanas, Universidade de São Paulo.

VALVERDE, O. "Metodologia da Geografia Agrária". In: Geografia Agrária do Brasil. Rio de Janeiro : INEP/MEC .1964. p. 11-37. . Estudos de Geografia Agrária Brasileira. Petrópolis: Ed. Vozes, 1985.

WAIBEL, L. Capitulos de Geografia Tropical e do Brasil. Rio de Janeiro, IBGE, 1958.

WITTER, J. S. USP 50 anos. Registros de um Debate. São Paulo: Edusp, 2006. (2a edição). 